\author{
MS17 P18 \\ Elaboration and charactérization new ferroelectric \\ solid solution with «TTB» structure by \\ mechanosynthesis M. Khachane ${ }^{1}$, A. Castro ${ }^{2}, M$. \\ Elaatmani $^{1}$, A. Moure ${ }^{2}$, A. Zegzouti ${ }^{1}$ and M. Daoud ${ }^{1}$. \\ 1 : Laboratoire de Chimie du Solide Minéral, Département \\ de Chimie, Faculté des Sciences Semlalia, Université Cadi \\ Ayyad BP : 2390, Marrakech, Maroc. \\ 2 : Institut des Sciences des Matériaux de Madrid, CSIC, \\ Cantoblanco, 28049 Madrid, Spain. \\ E-mail : m.khachane@ucam.ac.ma
}

Keywords: Ferroelectrics, mechanosynthesis, $\mathrm{X}$ ray diffraction.

Compounds with tetragonal tungsten-bronze structure (TTB) constitute one of most important family of ferroelectric materials, after that of perovskite-like structures or derived. Among materials with this structure, the ones with general formula $\mathrm{A}_{2} \mathrm{BNb}_{5} \mathrm{O}_{15}$ (where $\mathrm{A}$ : alkaline-earth cation and $\mathrm{B}$ : alkaline cation) as $\mathrm{Ba}_{2} \mathrm{NaNb}_{5} \mathrm{O}_{15}$, have particularly powerful electro-optical, pyrolectric and piezoelectric properties [1].

Barium and sodium niobate with $\mathrm{Ba}_{2} \mathrm{NaNb}_{5} \mathrm{O}_{15}$ composition (hereinafter called BNNO), studied in this work, is a ferroelectric compound with nonlinear and electro optic applications, in particular for the generation of the second harmonic with 0.53 starting from $1.06 \mathrm{~m}$ [2-4]. At room temperature, BNNO crystallizes with orthorhombic symmetry, and it becomes tetragonal above $260{ }^{\circ} \mathrm{C}[5]$.

Ferroelectric ceramics are usually processed by traditional solid state reaction at high temperature, but during the last years a new method of synthesis by mechanochemical activation has been successfully used. The mechanoactivation was developed for the synthesis of intermetallic materials, alloys and nanocrystalline materials [6-8]. Actually, mechanosynthesis is developed to be used for synthesis off ferroelectric compounds with different structures: pérovskite [9], Aurivillius [10] and TTB structure [11]. Mechanical activation is usually the result of disorder of the crystal and generation of defects that cause the decrease of the activation barrier for reaction [12]. Mechanical treatment is a way to modify the conditions in which chemical reactions usually take place. During the high energy milling, the particle size of the crystals is reduced, the homogeneity of the mixture is increased, and in most of cases the solid becomes more reactive. Furthermore, the obtained high reactivity and low particle size facilitate the sintering process, being possible to obtain high density ceramics at low temperatures [9]. In this work, a solid solution was synthesis by mechanosynthesis. The same solid solution was obtained by solid reaction at high temperature [13]. For milling we try two times in order to study the effect of the time in the formation off ferroelectric compounds. The obtained powders were characterized by $\mathrm{X}$ ray diffraction in room temperature and high temperature and by scanning electron microscopy.

[1] : Philipe Sciau, Gilbert Calvarin and Jean Ravez, Acta Cryst. (1999). B55, 459-466

[2] : D. F. O'Kane, E.A. Geiss, G. Burns, ET B.A. Scott, Bull. Amer. Phys. Soc. 12, 1079 (1967).

[3] : J.E. Geusic, H.J. Levinstein, J.J. Rubin, S. Singh, ET L. G. J. E. Geusic, H. J. Levinstein, S. Singh, R .C. Smith, ET L. G. Van Uitert, Appl. Phys. Lett. 12, 309 (1968).
[4] : Groen, S. Maassen, W.C. Keur, J. Eur. Ceram. Soc. 21 (2001) 1689-1692.

[5] : J. J. Rubin, L. G. Van Uitert et H. J. Levinstein, J. Cryst. Growth. 1, 315 (1969).

[6] : J. Benjamin, Sci. Am. 234 (1976) 40-49.

[7] : J. Ding, W. Miao, P. McCormick, R. Street, Appl. Phys. Lett. 67 (1995) 3804-3806.

[8] : A. Giri, Adv. Mater. 9 (1997) 163-166.

[9] : Hungría, A.B. Hungría, A. Castro, J. Solid State Chem. 177 (2004) 1559-1566.

[10] : P. Ferrer, J. E. Iglesias, * and A. Castro, Chem. Mater. 16 (2004), 1323-1329

[11] : H. A. M. Van, W.A. Van Uitert, Appl. Phys. Lett. 11, 269 (1967).

[12] : V.V. Boldyrev, K. Tkacova, J. Mater. Synthesis Processing, 8 (2000) 121.

[13] : M. Khachane, A. Moure, M. Elaatmani, A. Zegzouti, M. Daoud, A. Castro, Research Bulletin, volume 41, issue 10, 12 Octobre 2006, 1798-1805.

\section{MS17 P19}

Synthesis and Solid State Structure of the Three New Cu(I)-diazabutadiene Complexes Reza Kia ${ }^{a}$, Valiollah Mirkhani ${ }^{\mathrm{a}}$, Kenneth D.M. Harris ${ }^{\mathrm{b}}$, Zhigang Pan $^{\mathrm{b}}$, ${ }^{a}$ Chemistry Department, Isfahan University, Isfahan 81746-73441, Iran. ${ }^{b}$ School of Chemistry, Cardiff University, P.O. Box 912, Cardiff, Wales, CF10 3TB UK.

E-mail: zsrkk@yahoo.com

Keywords: copper(I) complexes, diazabutadiene ligand, powder diffraction

There has been a growing interest in the synthesis and characterization of copper(I) complexes of $\pi$-acceptor diimine ligands, due to the potential application of these complexes in catalytic processes, photosensitization reactions, light harvesting studies, and the design of supramolecular arrays [1]. The steric, electronic, and conformational effects imparted by the coordinated ligands play an important role in modifying the properties of the prepared metal complexes. Despite the huge amount of work aimed at understanding the properties and the structures of $\left[\mathrm{Cu}(\mathrm{NN})_{2}\right]^{+}$, where the $\mathrm{NN}$ ligand is different conjugated or unconjugated diimines or their derivatives, the chemistry of the $\left[\mathrm{Cu}(\mathrm{NN})_{2}\right]^{+}$complexes with 1,4diazabutadiene (DAB) ligands remains largely unexplored [2]. Bearing in mind all the above mentioned facts, we decided to pursue the studies of these complexes, which were focused mostly on the structural features. Herein, we report the synthesis and solid-state structures of the complexes from powder diffraction data.

[1] Bowmaker, G.A., Hanna, J.V., Healy, P.C., Reid, J.C., Pickard, C.E.F. White, A.H., J. Chem. Soc., Dalton Trans, 2000, 753.

[2] Horvath, O. Coord. Chem. Rev. 1994, 135, 303. 